\title{
ON THE DERIVATIVE OF A RATIONAL
}

\section{POLYNOMIAL WITH PRESCRIBED POLES}

\author{
DiNESH T., S. HANS AND BABITA TYAGI
}

Abstract. Let $p(z)=\sum_{v=0}^{n} a_{v} z^{v}$ be a polynomial of degree $n$ and $W(z)=\prod_{v=1}^{n}\left(z-a_{i}\right)$, where $\left|a_{i}\right|>1, j=1,2, \ldots n$. If $r(z)=p(z) / W(z)$ be a rational function does not vanish in $|z|>1$. The aim of this paper is to obtained some generalization of an inequality due to Xin Li, R. N. Mohapatra and R.S. Rodriguez [ Inequality (12), J. London Math. Soc. 51 (20), 1995, pp. 523-531] for the polynomial $r(z)$ having all its zeros in $|z| \leqslant k$ and other related results.

Mathematics subject classification (2020): 30A15, 30C10, $26 \mathrm{D} 07$.

Keywords and phrases: Rational function, derivative, zeros, poles.

\section{REFERENCES}

[1] A. Aziz And B. A. Zargar, Some Properties of Rational Functions with Prescribed Poles, Canad. Math. Bull., 42 (4), 1999, pp. 417-426.

[2] X. LI, A Comparison Inequality for Rational Functions, Proc. Ame. Math. Soci., 139 (5), 2011, pp. 1659-1665.

[3] X. Li, R. N. Mohapatra, AND R. S. RodGRIGUEZ, Bernstein-type inequalities for rational functions with prescribed poles, J. London Math. Soc., 51 (20), 1995, pp. 523-531.

[4] Q. I. Rahman And G. Schmeisser, Analytic Theory of Polynomials, Oxford Univ. Press., (2002).

[5] D. Tripathi, S. Hans, A. A. Mogbademu And BABita Tyagi, Inequality for Derivatives of Rational functions, J. Inter. Math., 21 (1), 2018, pp. 157-169. 